\title{
Trilha Interpretativa de Samambaias e Licófitas no Parque Nacional da Tijuca, Rio de Janeiro
}

\author{
Monira Bruno Bicalho ${ }^{1}$ \& Claudine M. Mynssen ${ }^{2}$
}

Recebido em 16/10/2019 - Aceito em 09/04/2020

1 Escola Nacional de Botânica Tropical, Programa de Pós-Graduação Profissional, Instituto de Pesquisas Jardim Botânico do Rio de Janeiro,
Rua Pacheco Leão 915, Rio de Janeiro/RJ, Brasil. CEP: 22.460-030 < monirabicalho@gmail.com>
2 Instituto de Pesquisas Jardim Botânico do Rio de Janeiro, Rua Pacheco Leão 915, Rio de Janeiro/RJ, Brasil. CEP: 22.460-030
<cmynssen@gmail.com>

RESUMO - O Parque Nacional da Tijuca, localizado na cidade do Rio de Janeiro, é uma das maiores unidades de conservação situadas em um centro urbano. Possui 3.953ha de área, divididos em quatro setores: Floresta da Tijuca; Serra da Carioca; Pedra Bonita e Pedra da Gávea; e Pretos Forros e Covanca. Os três primeiros setores estão abertos ao público e registram a maior visitação entre os parques brasileiros. É caracterizado pela grande variedade de habitat com altitudes que variam de 80 a $1.021 \mathrm{~m}$; possui afloramentos rochosos, cursos e quedas d'água. Abriga mais de um terço das espécies de samambaias e licófitas indicadas para o estado do Rio de Janeiro, incluindo endêmicas e raras. As trilhas existentes possuem diferentes graus de dificuldade. Assim, este estudo fez como recorte a Trilha dos Estudantes, por ser autoguiada e possuir placas interpretativas previamente instaladas, que favorecem o reconhecimento desse grupo vegetal pelos estudantes. Os espécimes foram fotografados, coletados, herborizados, identificados e depositados no herbário do Instituto de Pesquisas Jardim Botânico do Rio de Janeiro. Assim, foram selecionadas 21 espécies de samambaias e licófitas para compor um roteiro e um guia fotográfico com a finalidade de difundir o conhecimento dos grupos na Trilha dos Estudantes.

Palavras-chave: Interpretação ambiental; Mata Atlântica; prática educacional; pteridófitas; Trilha dos Estudantes.

\section{Interpretative Trail of Ferns and Lycophytes in the Tijuca National Park, Rio de Janeiro}

\begin{abstract}
Tijuca National Park, located in the city of Rio de Janeiro, is one of the largest conservation units in an urban center. It has 3.953ha of area divided into four sectors: Floresta da Tijuca, Serra da Carioca, Pedra Bonita and Pedra da Gávea and Pretos Forros and Covanca. The first three sectors are open to the public and register the largest visitation among the Brazilian Parks. It is characterized by the great variety of habitat with altitudes ranging from 80 to $1.021 \mathrm{~m}$, has rocky outcrops, streams and waterfalls. It harbour more than a third of ferns and lycophytes species indicated for the state of Rio de Janeiro including endemic and rare. Existing trails have varying degrees of difficulty. Thus, this study clipped the Student's Trail, because it is self-guided and has previously installed interpretive plates that favor the recognition of this plant group by students. The specimens were photographed, collected, herborized, identified and deposited in the Research Institute Rio de Janeiro Botanical Garden herbarium. Thus, 21 ferns and lycophytes species were selected to compose a script and a photographic guide in order to spread the knowledge of the groups in the Student's Trail.
\end{abstract}

Keywords: Atlantic forest; educational practice; environmental interpretation; pteridophytes; Student's Trail.

\section{Sendero interpretativo de helechos y lycophytes en el Parque Nacional Tijuca, Rio de Janeiro}

RESUMEN - El Parque Nacional Tijuca, ubicado en la ciudad de Río de Janeiro, es una de las unidades de conservación más grandes en un centro urbano. Tiene 3.953ha de área dividida en 
cuatro sectores: Floresta da Tijuca, Serra da Carioca, Pedra Bonita e Pedra da Gávea, y Pretos Forros e Covanca. Los primeros tres sectores están abiertos al público y registran las visitas más grandes entre los parques brasileños. El Parque Nacional Tijuca se caracteriza por la gran variedad de habitat con altitudes que van desde 80 hasta $1021 \mathrm{~m}$, tiene afloramientos rocosos, arroyos y cascadas. Alberga más de un tercio de los helechos y especies de licofitas indicados para el estado de Río de Janeiro, incluidos los endémicos y raros. Los senderos existentes tienen diferentes grados de dificultad. Por lo tanto, este cortó la pista de Estudiantes, porque es autoguiada y ha instalado previamente placas interpretativas que favorecen el reconocimiento de este grupo de plantas por parte de los estudiantes. Las muestras fueron fotografiadas, colectadas, herborizado, identificadas y depositadas en el herbario del Instituto de Investigación Jardín Botánico de Río de Janeiro. Por lo tanto, se seleccionaron 21 especies de helechos y lycophytes para componer un guión y un guía fotográfico con el fin de difundir el conocimiento de los grupos en el Sendero Estudiantil.

Palabras clave: Bosque atlántico; interpretación ambiental; práctica educativa; pteridófitas; Sendero Estudiantil.

\section{Introdução}

O Parque Nacional da Tijuca apresenta um dos mais bem-sucedidos projetos de reflorestamento do mundo, visto que, durante o século XVIII, a área da floresta foi desmatada para que desse lugar a plantações (Drummond 1988). O plantio de café, a partir de 1760 , e a chegada da Família Real, em 1808, são considerados como responsáveis pela destruição de grande parte da floresta (Drummond 1988, IBASE 2006). O reflorestamento se deu por ordem do governo imperial, com a desapropriação de terras com o intuito de solucionar os problemas enfrentados pela seca ocorrida entre os anos de 1824 e 1844 (Drummond 1988). Assim, no período de 1862 até 1943, foram plantadas mais de 90 mil mudas de árvores de florestas nativas e exóticas, além do embelezamento paisagístico e da transformação em áreas de lazer para a população (Maya 1967, Drummond 1988, IBASE 2006, Beliani \& Borges 2016).

Atualmente, o Parque Nacional da Tijuca está dividido em quatro setores não conectados entre si: a Floresta da Tijuca, Serra da Carioca, Pedra Bonita/Pedra da Gávea e Pretos Forros/ Covanca, e é uma unidade de conservação federal de proteção integral (ICMBio 2008). Nos últimos anos, as unidades de conservação (UCs) contabilizaram um aumento do número de visitantes e este foi considerado o parque mais visitado no Brasil entre os anos de 2012 e 2016, com uma média 2,9 milhões de visitantes por ano (Freitas et al. 2002, ICMBio 2017).

Acredita-se que grande parte das trilhas existentes - pelo menos desde o século XIX
- no Parque Nacional da Tijuca foi utilizada nas ações de reflorestamento e por membros da Corte (Malta \& Costa 2009). Hoje, possui $128 \mathrm{~km}$, divididos em 52 trilhas, sendo 46 delas abertas ao público; algumas possuem sinalização direcional ou interpretativa, como a Trilha dos Estudantes (ICMBio 2008, ICMBio 2017, Siqueira et al. 2013).

Um estudo comparativo com livros didáticos do ensino básico indicou um déficit de informações sobre samambaias e licófitas (Bicalho 2015), além disso, sabe-se que mais de um terço da flora de samambaias e licófitas do estado do Rio de Janeiro ocorre no Parque Nacional da Tijuca (Bicalho et al., dados inéditos). Considerando que a trilha interpretativa é um facilitador de acesso ao conhecimento, uma nova abordagem da Trilha dos Estudantes é proposta neste trabalho. Assim, a diversidade de espécies de samambaias e licófitas ocorrentes ao longo desse trajeto interpretativo subsidiará atividades educacionais propostas para os ensinos fundamental e médio. Para tal, foi elaborado um roteiro de campo ilustrado, um roteiro para professores e um guia fotográfico.

\section{Material e Métodos}

\section{Área de estudo}

O Parque Nacional da Tijuca (PARNA da Tijuca), criado em 1961 pelo Decreto Federal $\mathrm{n}^{\circ} 50.923$, está localizado no centro da cidade do Rio de Janeiro, entre as coordenadas $22^{\circ} 55^{\prime} \mathrm{S}$ $23^{\circ} 00^{\prime} \mathrm{S}$ e $43^{\circ} 11^{\prime} \mathrm{W} 43^{\circ} 19^{\prime} \mathrm{W}$ (Figura 1). Situado no Maciço da Tijuca, o PARNA é uma área de floresta ombrófila densa (altomontana, montana e submontana) em avançado estado de regeneração 


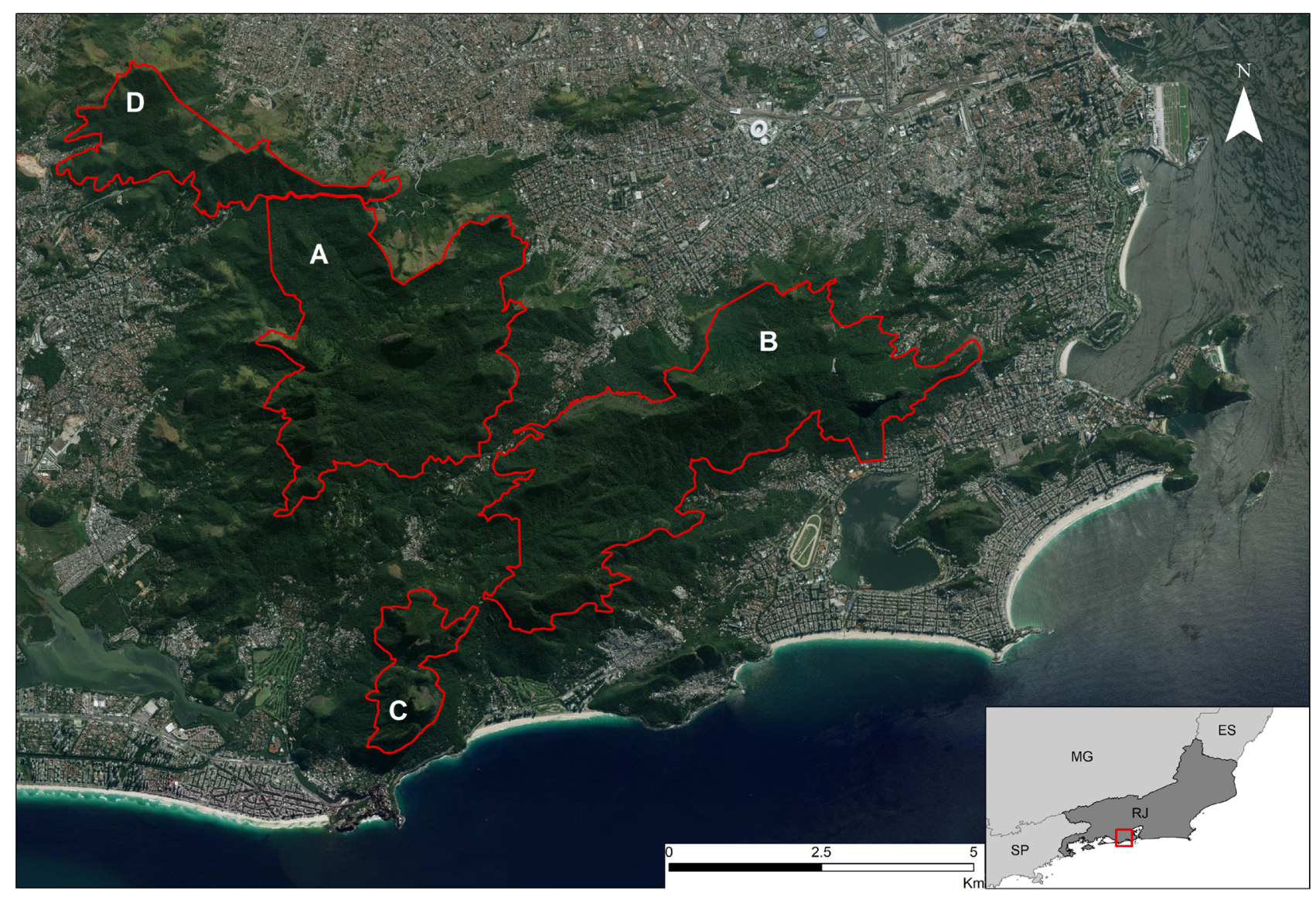

Figura 1 - Localização do Parque Nacional da Tijuca, na cidade do Rio de Janeiro, com indicações dos setores. A - Floresta da Tijuca; B - Serra da Carioca; C - Pedra Bonita/Pedra da Gávea; e D - Pretos Forros e Covanca.

que abriga fragmentos da Mata Atlântica original. É formado por quatro setores descontínuos: Floresta da Tijuca (Setor A), Serra da Carioca (Setor B), Pedra Bonita/Pedra da Gávea (Setor C) e Pretos Forros e Covanca (Setor D). A Trilha dos Estudantes, localizada no setor Floresta da Tijuca, é dividida em três partes, interrompidas pela estrada de acesso, totalizando $1.280 \mathrm{~m}$ de percurso e $876 \mathrm{~m}$ de trilha propriamente dita. Atualmente, existem 13 placas que ressaltam informações relevantes sobre o relevo, afloramentos rochosos e dados sobre a dinâmica da floresta no PARNA (ICMBio 2008, Siqueira et al. 2013). Essa trilha foi escolhida por ser de baixo nível de dificuldade, bem sinalizada, de fácil acesso e por possuir placas interpretativas. Também é muito popular entre os visitantes, sendo utilizada em educação ambiental e por grupos escolares.

O clima é classificado como tropical de altitude, com temperatura média oscilando entre $22^{\circ} \mathrm{C}$ e $25^{\circ} \mathrm{C}$, com média máxima em $27,2^{\circ} \mathrm{C}$ e média mínima de $16,9^{\circ} \mathrm{C}$. A precipitação média é de $2.500 \mathrm{~mm} / \mathrm{ano}$, com intensificação nos quatro primeiros meses do ano. O Maciço possui áreas ao nível do mar, e o Pico da Tijuca, com $1.021 \mathrm{~m}$, é ponto culminante. O solo é predominantemente de latossolo, ocorrendo também litossolo $e$ cambissolo (ICMBio 2008).

\section{Coleta de dados}

As amostras de samambaias e licófitas foram coletadas entre os anos de 2017 e 2018, em visitas bimensais realizadas ao longo da Trilha dos Estudantes, prensadas e herborizadas (Fidalgo \& Bononi 1984). Os espécimes foram identificados e incluídos na coleção do herbário do Instituto de Pesquisas Jardim Botânico do Rio de Janeiro (RB). 


\section{Pontos interpretativos e roteiro de campo}

A seleção dos pontos interpretativos baseou-se no método proposto por Magro e Freixêdas (1998), que consiste em selecionar $e$ indicar os pontos com maior atratividade para o visitante (Indicadores de Atratividade de Pontos Interpretativos). Assim, as placas interpretativas previamente posicionadas $e$ um poste de localização foram selecionados, totalizando nove pontos: Placa 01 (Trilha dos Estudantes); Placa 03 (Mata Atlântica); Poste da Cascatinha; Placa 04 (A Importância da Serapilheira); Placa 05 (Cascatinha Taunay); Parede Úmida; Placa 07 (Função das Florestas); Placa 08 (Paredão Rochoso) e Placa 14 (Centro de Visitantes). Os espécimes apontados na trilha correspondem àqueles mais representativos $e \mathrm{de}$ fácil visualização.
O roteiro de campo foi elaborado para nortear o visitante, ressaltando as informações relevantes a serem observadas em cada ponto interpretativo. O Guia Fotográfico das espécies encontradas foi elaborado de acordo com o modelo proposto pelo Field Museum Guide e está disponível online (https://fieldguides.fieldmuseum. org/guides/guide/1154).

\section{Resultados e Discussão}

O Parque Nacional da Tijuca abriga cerca de 260 espécies de samambaias e licófitas (Bicalho et al., dados inéditos), o que corresponde a mais de um terço da flora do estado do Rio de Janeiro. Acredita-se que a grande diversidade de microhabitat do Parque Nacional da Tijuca favoreça esse número. É sabido que, nas regiões

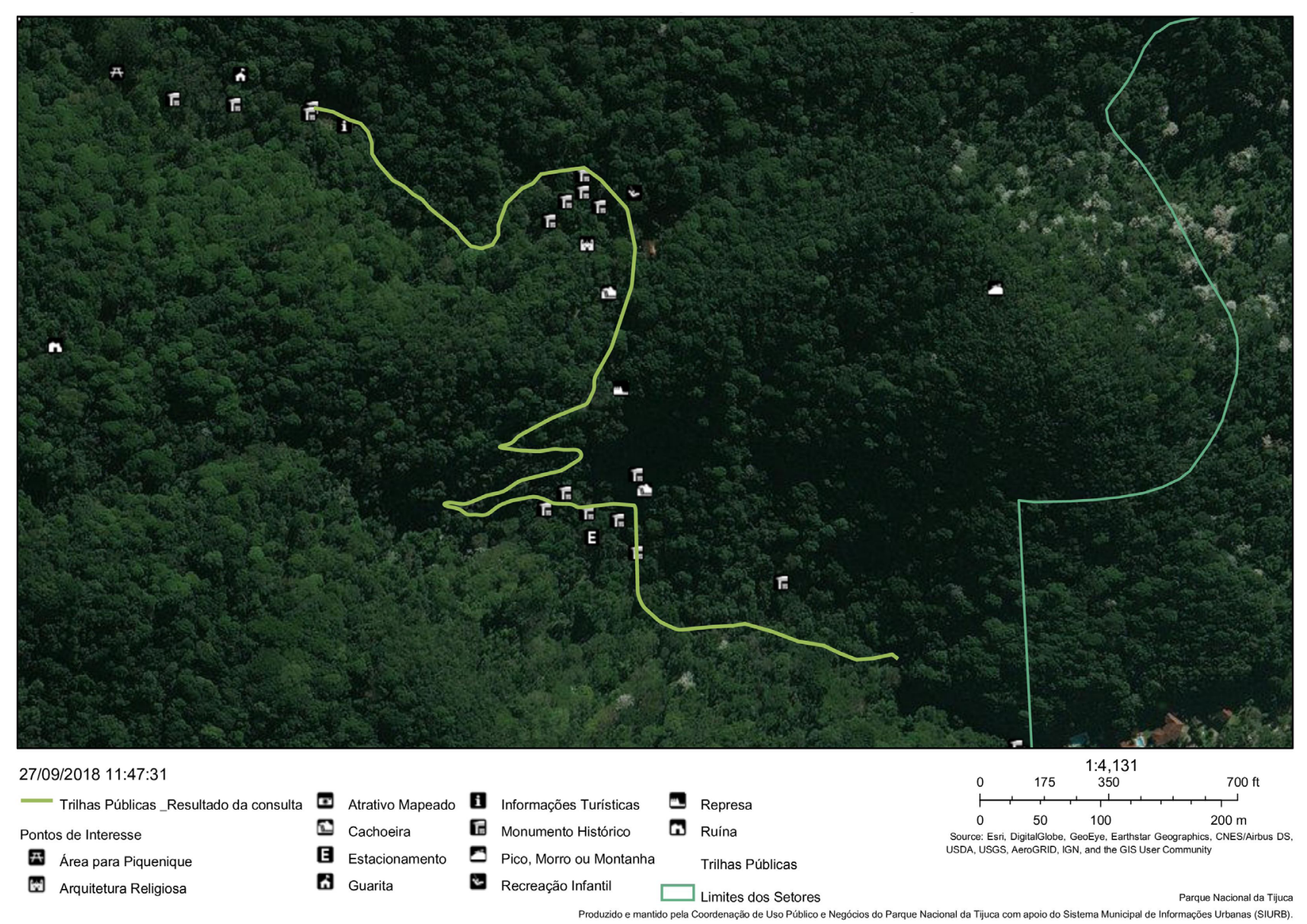

Figura 2 - Traçado da Trilha dos Estudantes, em verde claro, no Parque Nacional da Tijuca. Mapa produzido e mantido pela Coordenação de Uso Público e Negócios do Parque Nacional da Tijuca, com apoio do Sistema Municipal de Informações Urbanas (SIURB). 
montanhosas tropicais, a elevada heterogeneidade de ambientes com microclimas, elevações $e$ substratos distintos favorece a alta diversidade de espécies de samambaias e licófitas (Tryon 1985, Moran 1995). No Brasil, são reconhecidas 1.253 espécies de samambaias e licófitas, sendo 620 no estado do Rio de Janeiro (Prado et al. 2015).

As trilhas interpretativas são caminhos em ambientes naturais que, além de propiciar a integração do visitante com o ambiente, podem ser utilizadas como um mecanismo para a prática educacional formal, não formal e de divulgação da ciência (Marandino et al. 2004, Zanin 2006, Borges et al. 2013). Além disso, trilhas interpretativas podem auxiliar a compreensão dos temas estudados anteriormente em sala de aula e estimular o processo de ensino-aprendizagem. Em muitos casos, servem como facilitadoras em conceitos considerados de difícil aprendizagem, $e$ provocam interesse em temas científicos (Borges et al. 2013, Costa et al. 2014). Estudos apontam que aulas realizadas em ambiente não formal, como uma trilha interpretativa, levam a uma melhor compreensão dos conceitos científicos (Seniciato e Cavassan 2004).

Os PARNAs têm como um de seus objetivos a integração do homem com a natureza, além da preservação de áreas naturais de ameaças reais ou potenciais (Fernandez 2011). Considerando que o Parque Nacional da Tijuca está no entorno urbano da cidade do Rio de Janeiro, é um espaço que promove a interação e oferece atrativos para visitantes - sejam turistas ou estudantes.

Assim como Siqueira et al. (2015), a Trilha dos Estudantes foi selecionada por possuir relevo plano em quase todo o seu percurso de $1.280 \mathrm{~m}$ de extensão e ser considerada de fácil execução.

Os espécimes mais abundantes ou localizados em áreas de melhor visualização foram selecionados nos nove pontos interpretativos, indicados no roteiro de campo (Tabela 1); dois deles possuem área de descanso. Um total de 12 famílias, 17 gêneros e 21 espécies de samambaias e licófitas (Tabela 2) foi analisado e indicado ao longo da trilha. Esse total representa 8,08\% do total de espécies que ocorrem no Parque Nacional da Tijuca, e 3,38\% do total de espécies que ocorrem no Rio de Janeiro (Prado et al. 2015, Bicalho et al. dados inéditos).
A utilização de mecanismos para ilustrar uma visita a um ambiente natural auxilia o enriquecimento da experiência para o visitante. Lisboa et al. (2016) indicam que a correta identificação dos espécimes em uma trilha pode estimular os visitantes a buscar informações adicionais posteriormente; assim, foi produzido um guia fotográfico (https:// fieldguides.fieldmuseum.org/guides/guide/1154) para auxiliar na criação de uma identidade do visitante com o tema trabalhado na trilha.

A Trilha dos Estudantes oferece subsídios para ser realizada na modalidade autoguiada, fornecendo autonomia ao visitante (Zanin 2006, ICMBio 2008, Pellin et al. 2010). Desta forma, e por já possuir recursos como placas, guias $e$ fôlderes, serve de importante mecanismo para a interpretação ambiental e como representante da biodiversidade local (Mendes et al. 2007).

\section{Considerações Finais}

A Trilha dos Estudantes possui grande relevância para a interpretação ambiental, com valores ecológicos, históricos e sociais (ICMBio 2008), servindo como um mecanismo para a educação ambiental desenvolvida no Parque. As 21 espécies apontadas ao longo da trilha foram selecionadas por serem de melhor visualização no trajeto, pelas suas características morfológicas variadas ou por ocuparem diferentes habitat. Considerando o total de espécies indicadas, esse valor corresponde a 8,08\% das espécies ocorrentes no Parque Nacional da Tijuca. Acredita-se que a observação dessas espécies ao longo da Trilha dos Estudantes favoreça o conhecimento do grupo, uma vez que trará muitas outras informações associadas.

Com a implementação de uma nova abordagem à Trilha dos Estudantes, espera-se que um número maior de pessoas se identifique com o tema de samambaias e licófitas, observando a diversidade do grupo e suas relações com a dinâmica do ambiente em que está localizado. Uma trilha interpretativa auxilia na interação dos visitantes com o meio natural, fazendo com que o assunto abordado seja compreendido de forma mais dinâmica, além de instigar a troca de saberes entre docentes/monitores e alunos/visitantes (Alvarenga et al. 2018). 
Tabela 1 - Roteiro a ser executado por visitantes e professores ao longo da Trilha dos Estudantes, com informações sobre o percurso, pontos a serem observados em cada parada, pontos de descanso $e$ atividades indicadas.

\begin{tabular}{|c|c|}
\hline Ponto & Abordagem \\
\hline \multirow{7}{*}{ Início da Trilha } & Informações básicas sobre o trajeto \\
\hline & $\begin{array}{l}\text { Informar a necessidade de se prestar atenção no trajeto e no solo onde se } \\
\text { pisa }\end{array}$ \\
\hline & $\begin{array}{l}\text { Orientar os alunos/visitantes para não se afastarem dos professores e/ou } \\
\text { guias }\end{array}$ \\
\hline & $\begin{array}{l}\text { Não retirar pedras, plantas, flores ou qualquer outra coisa encontrada ao } \\
\text { longo da trilha }\end{array}$ \\
\hline & Não riscar pedras, troncos, bancos \\
\hline & Não alimentar ou mexer nos animais \\
\hline & $\begin{array}{l}\text { Informar que todo o lixo que for produzido durante o trajeto será } \\
\text { guardado e adequadamente descartado }\end{array}$ \\
\hline \multirow{4}{*}{ Ponto interpretativo 1 (placa 01) } & Mostrar a diversidade morfológica entre as espécies \\
\hline & $\begin{array}{l}\text { Mostrar os tipos de indumentos (pelos ou escamas) que podem ser } \\
\text { observados }\end{array}$ \\
\hline & $\begin{array}{l}\text { Procurar se há alguma espécie fértil com soros e comparar a diferença } \\
\text { entre eles }\end{array}$ \\
\hline & Procurar se há alguma vernação circinada (báculo) \\
\hline \multirow{2}{*}{ Ponto interpretativo 2 (placa 03) } & $\begin{array}{l}\text { Mostrar uma samambaia arborescente, cujo caule ereto possa atingir } \\
\text { muitos metros de altura }\end{array}$ \\
\hline & $\begin{array}{l}\text { Mostrar a presença de espinhos e escamas que dão proteção no } \\
\text { desenvolvimento de frondes jovens e ação de predadores }\end{array}$ \\
\hline \multirow{3}{*}{ Ponto interpretativo 3 (poste Cascatinha) } & Mostrar a diferença entre espécies rupícolas e terrestres \\
\hline & Mostrar a Selaginella como única representante das licófitas na trilha \\
\hline & $\begin{array}{l}\text { Mostrar a diferença entre espécies que apresentam frondes monomorfas } \\
\text { (Blechnum polypodioides) e dimorfas (Olfersia corcovadensis) }\end{array}$ \\
\hline Ponto interpretativo 4 (placa 04) & $\begin{array}{l}\text { Mostrar as espécies que ocorrem preferencialmente onde há acúmulo de } \\
\text { serapilheira }\end{array}$ \\
\hline Ponto interpretativo 5 (placa 05) & Ponto de descanso \\
\hline Ponto interpretativo 6 (Parede Úmida) & $\begin{array}{l}\text { Mostrar espécies que ocorrem em lugares úmidos e ressaltar a } \\
\text { importância da água no ciclo de vida }\end{array}$ \\
\hline Ponto interpretativo 7 (placa 07) & $\begin{array}{l}\text { Mostrar paredão com Hymenophyllaceae; as frondes podem ser muito } \\
\text { membranáceas com uma fileira de células em espessura }\end{array}$ \\
\hline Ponto interpretativo 8 (placa 08) & Mostrar espécies que ocorrem no paredão rochoso \\
\hline \multirow{3}{*}{ Ponto interpretativo 9 (placa 14) } & $\begin{array}{l}\text { Informar que há espécies de samambaias arborescentes ameaçadas de } \\
\text { extinção (Dicksonia sellowiana Hook.) por causa da extração de xaxim }\end{array}$ \\
\hline & $\begin{array}{l}\text { Mostrar o Centro de Visitantes e as exposições sobre a história do Parque } \\
\text { Nacional da Tijuca }\end{array}$ \\
\hline & Parada para o lanche/ponto para descanso \\
\hline
\end{tabular}


Tabela 2 - Lista de espécies de samambaias e licófitas indicadas ao longo da Trilha Interpretativa dos Estudantes, no Parque Nacional da Tijuca, RJ. *Espécies com foto

\begin{tabular}{|c|c|c|c|}
\hline Família & Táxon & Voucher & Ponto interpretativo \\
\hline \multirow{2}{*}{ Anemiaceae } & Anemia mandioccana Raddi* & Mynssen, C.M. 1356 (RB00726492) & 1 e 6 \\
\hline & Anemia phyllitidis (L.) Sw. & Damasceno, R.N. 636 (RB00689835) & 1 \\
\hline \multirow{3}{*}{ Blechnaceae } & Blechnum occidentale L.* & Bicalho, M. 63 (RB01402632) & 5 \\
\hline & Blechnum polypodioides Raddi* & Bicalho, M. 61 (RB01402630) & 3 \\
\hline & $\begin{array}{l}\text { Neoblechnum brasiliense (Desv.) } \\
\text { Gasper \& V.A.O. Dittrich* }\end{array}$ & Carauta, J.P.P. 2015 (RB00644491) & 9 \\
\hline \multirow{3}{*}{ Cyatheaceae } & $\begin{array}{l}\text { Cyathea corcovadensis (Raddi) } \\
\text { Domin* }\end{array}$ & Bovini, M.G. 903 (RB00707439) & 2 \\
\hline & Cyathea delgadii Sternb.* & Horta, P.P. 14388 (RB00643720) & 9 \\
\hline & Cyathea leucofolis Domin & Schwacke, P. 6659 (RB00643761) & 1 \\
\hline Dennstaedtiaceae & $\begin{array}{l}\text { Dennstaedtia globulifera (Poir.) } \\
\text { Hieron }\end{array}$ & Carauta, J.P.P. 2070 (RB00655531) & 5 \\
\hline \multirow{4}{*}{ Dryopteridaceae } & Bolbitis serratifolia Schott & Sylvestre, L.S. 2213 (RB00710255) & 6 \\
\hline & Ctenitis falciculata (Raddi) Ching* & Bicalho, M. 62 (RB01402631) & 4 \\
\hline & $\begin{array}{l}\text { Megalastrum grande (C.Presl) } \\
\text { A.R.Sm. \& R.C.Moran* }\end{array}$ & Bicalho, M. 67 (RB01402636) & 4 e 7 \\
\hline & Olfersia cervina (L.) Kunze & Sylvestre, L.S. 2218 (RB00710260) & 3 e 8 \\
\hline Hymenophyllaceae & $\begin{array}{l}\text { Vandenboschia rupestris (Raddi) } \\
\text { Ebihara \& K. Iwats* }\end{array}$ & Schwacke, P. 934 (RB00650094) & 7 \\
\hline \multirow{2}{*}{ Marattiaceae } & Danaea geniculata Raddi* & Bicalho, M. 58 (RB01402626) & 1 e 3 \\
\hline & Eupodium kaulfussii (J.Sm.) J.Sm. & Bicalho, M. 66 (RB01402635) & 1 \\
\hline Polypodiaceae & $\begin{array}{l}\text { Campyloneurum decurrens (Raddi) } \\
\text { C.Presl* }\end{array}$ & Bicalho, M. 68 (RB01402637) & 8 \\
\hline Pteridaceae & Adiantum raddianum C.Presl & Bicalho, M. 64 (RB01402633) & 5 \\
\hline Saccolomataceae & $\begin{array}{l}\text { Saccoloma brasiliense (C.Presl) } \\
\text { Mett. }\end{array}$ & Bicalho, M. 59 (RB01402627) & 3 \\
\hline Selaginellaceae & Selaginella flexuosa Spring* & Bicalho, M. 60 (RB01402629) & 3 \\
\hline Thelypteridaceae & $\begin{array}{l}\text { Steiropteris polypodioides (Raddi) } \\
\text { Salino \& T.E. Almeida }\end{array}$ & Mynssen, C.M. 1300 (RB00701375) & 1 \\
\hline
\end{tabular}



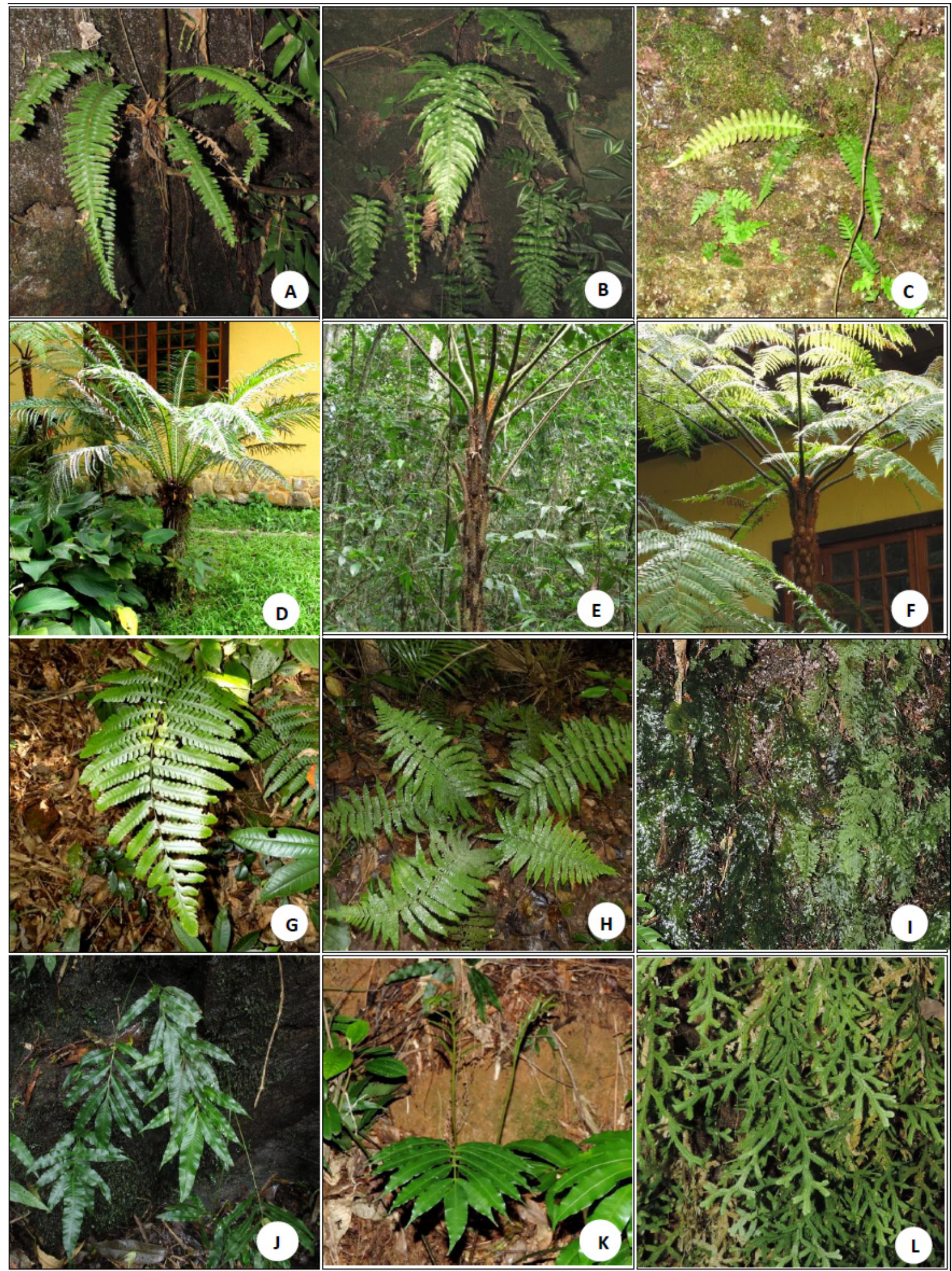

Figura 3 - Espécies frequentes ao longo da trilha: A) Anemia mandioccana Raddi; B) Blechnum occidentale L.; C) B. polypodioides Raddi; D) Neoblechnum brasiliense (Desv.) Gasper \& V.A.O. Dittrich; E) Cyathea corcovadensis (Raddi) Domin; F) Cyathea delgadii Sternb; G) Ctenitis falciculata (Raddi) Ching; H) Megalastrum grande (C.Presl) A.R.Sm. \& R.C.Moran; I) Vandenboschia rupestris (Raddi) Ebihara \& K. Iwats; J) Danaea geniculata Raddi; K) Campyloneurum decurrens (Raddi) C.Presl; L) Selaginella flexuosa Spring. 


\section{Agradecimentos}

Agradecemos ao Programa de Pósgraduação em Biodiversidade em Unidades de Conservação da Escola Nacional de Botânica Tropical; ao Instituto de Pesquisas Jardim Botânico do Rio de Janeiro, pela estrutura utilizada; e ao Parque Nacional da Tijuca, pela liberação do espaço durante o período de pesquisas.

\section{Referências Bibliográficas}

Alvarenga CA de, Oliveira CMVC de, Ferreira ALR, Silva PS da, Gregório FSF, Cesar GC de L \& Ribeiro LA. Trilha interpretativa para promoção da educação ambiental na Funcesi, Itabira Minas Gerais. Research, Society and Development, 7(1), 01-19, 2018.

Beliani E, de Moraes NA \& Borges LC. 2016. Um parque sob encantos e desencantos: a Floresta da Tijuca, do reflorestamento a patrimônio paisagístico mundial. In: Anais eletrônicos do $15^{\circ}$ Seminário Nacional de História da Ciência e da Tecnologia. Florianópolis, SC, 16 a 18 de novembro de 2016.

Bicalho MB. 2015. Análise crítica sobre o tema pteridófitas s.l. Abordado em livros do ensino médio. Monografia (Licenciatura em Ciências Biológicas). Universidade Veiga de Almeida. 30p.

Borges CM, Liberali G \& Silva RD. 2013. A Trilha Interpretativa como Prática Inovadora de Ensino de Educação Ambiental para Alunos do Ensino Fundamental em Poços de Caldas, MG. In: X Congresso Nacional de Meio Ambiente de Poços de Caldas.

Costa ESA da, Costa IAS da, Oliveira KS de \& Melo $\mathrm{AV}$ de. Trilhas interpretativas na área verde da escola como estratégia de ensino aprendizagem de conceitos ecológicos. Revista da SBEnBio, (07): 1820-1831, 2014.

Drummond JA. O jardim dentro da máquina: breve história ambiental da Floresta da Tijuca. Revista Estudos Históricos, 1(2): 276-298, 1988.

Fernandez ACF. Um Rio de florestas: uma reflexão sobre o sentido da criação dos parques na cidade do Rio de Janeiro. Estudos Históricos. 24(47): 141-161, 2011.

Fidalgo O \& Bononi V. 1984. Técnicas de coleta, preservação e herborização de material botânico. São Paulo: Instituto de Botânica, 62p.

Freitas WK de, Magalhães LMS \& Guapyassú M dos S. Potencial de uso público do Parque Nacional da Tijuca. Acta Scientiarum. Technology, 24: 1833-1842, 2002.

IBASE (Instituto Brasileiro de Análises Sociais e Econômicas). 2006. Parque Nacional da Tijuca Integrando proteção ambiental e participação social em áreas urbanas. IBASE. <http://www.ibase.br/ userimages/ap_ibase_pc_01e.pdf $>$. Acesso em: 20/09/2018.

ICMBio. 2008. Plano de Manejo do Parque Nacional da Tijuca. Brasília. <http://www.icmbio.gov.br/parnatijuca/ plano-de-manejo > . Acesso em: 25/09/2018.

ICMBio. 2017. Dados de Visitação 2007 - 2016. Coordenação Geral de Uso Público e Negócios. Brasília. <http://www.icmbio.gov.br/portal/images/ stories/comunicacao/noticias/2017/dados_de_ visitacao_2012_2016.pdf > . Acesso em: 25/09/2018.

Lisboa TDFB, Cielo-Filho R, Câmara CD \& da Silva WB. Aspectos botânicos e ecossistêmicos como subsídio à interpretação ambiental na trilha do Parque Municipal Farroupilha, Oeste do Paraná. Revista Brasileira de Educação Ambiental (RevBEA), 11(2): 74-90, 2016.

Magro TC \& Freixêdas VM. 1998. Trilhas: como facilitar a seleção de pontos interpretativos. Embrapa MeioNorte. Circular Técnica IPEF. n. 186.

Malta RR, Costa \& NMCD. Gestão do uso público em unidade de conservação: a visitação no Parque Nacional da Tijuca-RJ. Revista Brasileira de Ecoturismo, 2(03), 2009.

Marandino M, Silveira RVM da, Chelini MJ, Fernandes AB, Rachid V., Martins LC, Lourenço MF, Fernandes JA \& Florentino HA. 2004. A educação não formal e a divulgação científica: o que pensa quem faz. In: Atas do IV Encontro Nacional de Pesquisa em Ensino de Ciências.

Maya RO de C. 1967. A Floresta da Tijuca. Editora Bloch. 103p.

Mendes AF, de Souza AS \& Tabanez, MF. A Trilha Interpretativa das Árvores Gigantes do Parque Estadual de Porto Ferreira na modalidade autoguiada. Revista do Instituto Florestal, (19)2: 173-188, 2007.

Moran RC. 1995. The importance of mountains to Pteridophytes, with emphasis on Neotropical Montane Forests. P. 359-363. In: Churchill SP, Balslev H, Forero E \& Luteyn JL (orgs.) Biodiversity and Conservation of Neotropical Montane Forests. New Botanical Garden. 702p.

Pellin A, Scheffler SM \& Fernandes HM. Planejamento $e$ implantação de trilha interpretativa autoguiada na RPPN Fazenda da Barra (Bonito, Mato Grosso do Sul, Brasil). Nature and Conservation, 3(1): 6-26, 2010.

Prado J, Sylvestre L da S, Labiak PH, Windisch PG, Salino A, Barros ICL, Hirai RY, Almeida TE, Santiago ACP, Kieling-Rubio MA, Pereira A de N, Øllgaard B, Ramos CGV, Mickel JT, Dittrich VAO, Mynssen CM, Schwartsburd PB, Condack JPS, Pereira JBS \& Matos FB. Diversity of ferns and lycophytes in Brazil. Rodriguésia, 66(4): 1073-1083, 2015. 
Seniciato T. \& Cavassan O. Aulas de campo em ambientes naturais $e$ aprendizagem em ciências: um estudo com alunos do ensino fundamental. Ciência \& Educação (Bauru), (10)1: 133-147, 2004.

Siqueira AE de, Soares AJ, Barreto Junior AO, Donato AM, Tartaglia AR, Barros DB de S, Borim DCDE, Palma LM, Rodrigues MN, Luz MVA da, Santos MA dos, Silva MCV da \& Haussig TR. 2013. Guia de Campo do Parque Nacional da Tijuca - Rio de Janeiro. UERJ/ IBRAG. 50p.

Tryon R. Fern speciation and biogeography. Proceedings of the Royal Society of Edinburgh, Section B: Biological Sciences, (86): 353-360, 1985.

Zanin EM. Projeto Trilhas Interpretativas - a extensão, o ensino e a pesquisa integrados à conservação ambiental e à educação. Vivências, 1(1): 26-35, 2006.

Biodiversidade Brasileira - BioBrasil.

Edição temática: Diálogos entre a Academia e a Gestão de Áreas Protegidas:

Programa de Pós-Graduação Profissional - Biodiversidade em Unidades de Conservação n. 2,2020

http://www.icmbio.gov.br/revistaeletronica/index.php/BioBR

Biodiversidade Brasileira é uma publicação eletrônica científica do Instituto Chico Mendes de Conservação da Biodiversidade (ICMBio) que tem como objetivo fomentar a discussão e a disseminação de experiências em conservação e manejo, com foco em unidades de conservação $e$ espécies ameaçadas. 